\title{
关注长江水质
}

“绿行之踪”社会实践

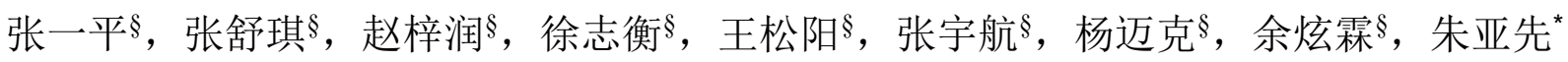
厦门大学化学化工学院, 福建 厦门 361005

摘要: 2018 年和 2019 年小学期, 厦门大学本科生 “绿行之踪” 社会实践队赴重庆、上海等长江流域主要城市进行社 会实践活动, 采集了当地的水样, 测定了水样中的磷酸根含量和高锰酸盐指数, 同时进行了水资源保护的宣传活动和网 络问卷调查。

关键词: 长江水质; 水质分析; 社会实践

中图分类号: G64; O6

\section{Focus on the Water Quality of Yangtze River: Social Practice of "Trace of the Green Line"}

\author{
Yiping Zhang ${ }^{\S}$, Shuqi Zhang ${ }^{\S}$, Zirun Zhao ${ }^{\S}$, Zhiheng Xu ${ }^{\S}$, Songyang Wang ${ }^{\S}$, Yuhang Zhang ${ }^{\S}$, \\ Maike Yang ${ }^{\S}$, Xuanlin Yu ${ }^{\S}$, Yaxian Zhu * \\ College of Chemistry and Chemical Engineering, Xiamen University, Xiamen 361005, Fujian Province, P. R. China.
}

\begin{abstract}
During the short term of 2018 and 2019, Xiamen University undergraduates' social practice team called "Trace of the Green Line" went to Chongqing, Shanghai and other major cities along Yangtze River to do some social practice activities. We collected the local water samples and determined the content of phosphate and permanganate index in water samples. At the same time, we had the promotion and the network questionnaire survey to promote the consciousness of protecting water resources.
\end{abstract}

Key Words: Water quality of Yangtze River; Water quality analysis; Social practice

\section{1 概述}

人的一切生命活动与生产活动都离不开水资源。我国属于淡水缺乏的国家, 人均可利用淡水资 源仅 $2200 \mathrm{~m}^{3}$, 是全球 13 个人均水资源最贫乏的国家之一 ${ }^{[1]}$ 。我国的水污染情况较为严重, 近年来 经过一系列治理目前已初见成效： 2018 年与 2017 年同比, 我国 I-III 类水质河长比例上升 $1.0 \%$, 劣 $\mathrm{V}$ 类水河长比例下降 $1.3 \%$; I-III 类水质湖泊的个数比例下降 $1.6 \%$, 富营养湖泊比例下降 $1.7 \%$; 全 年水质合格率在 $80 \%$ 及以上的集中式饮用水水源地的数量比例上升 $1.2 \%{ }^{[2]}$ 。

2018 年 5 月, 我们成立了 “绿行之踪” 社会实践队, 旨在通过实地调查, 了解我国长江流域的 水质情况, 并向社会大众宣传普及保护水资源的重要性。同年 7 月, “绿行之踪” 社会实践队赴重

收稿: 2020-04-19; 录用: 2020-04-22; 网络发表: 2020-05-18

”通讯作者, Email: yaxian@xmu.edu.cn

$\$ 2017$ 级或 2018 级本科生

基金资助：国家基础科学人才培养基金项目(J1310024) 
庆、宜昌、武汉、上海等地进行了实地采集水样, 水样采集后密封于聚乙烯塑料瓶中, 带回厦门大 学化学国家级实验教学示范中心进行测定。

2019 年 7 月, 实践队扩大规模, 再赴重庆等地进行水样采集和测定, 并通过微博、微信公众号 和调查问卷、实地采访等形式向群众宣传普及水资源保护的知识。

\section{2 水样测定}

2018 年, 实践队赴重庆、宜昌、武汉、上海采集水样, 测定了 12 个样品的磷含量和高锰酸盐 指数。2019 年, 实践队赴重庆、长沙、苏州、南昌、岳阳等地取样, 测定了近 100 个样品的磷含量、 高锰酸盐指数、氨氮含量、 $\mathrm{Ni}^{2+}$ 和 $\mathrm{F}^{-}$含量。在此简要介绍 “绿行之踪” 实践队在长江流域几个点采 集水样的磷含量与高锰酸盐指数测定情况。

\section{1 实验仪器与药品}

实验仪器：分光光度计(岛津 UV-3600)、电热板、水浴锅。

实验药品: 钼酸钠(分析纯)、硫酸、无水氯化亚锡(分析纯)、丙三醇(分析纯)、磷酸二氢钾(分析 纯)、蒸馏水、 $0.01 \mathrm{~mol} \cdot \mathrm{L}^{-1}$ 高锰酸钾溶液、 $0.01000 \mathrm{~mol} \cdot \mathrm{L}^{-1}$ 草酸钠溶液。

\section{2 磷钼蓝可见分光光度法测定磷含量}

磷是评价水质的重要指标之一, 化肥、冶炼、合成洗涤剂等行业的工业废水及生活污水中常含 有较大量磷。水中磷酸盐含量过高可导致富营养化, 造成藻类大量繁殖, 水质变坏, 鱼虾死亡 ${ }^{[3]}$ 。 经过查阅资料, 我们采用磷钼蓝可见分光光度法测定水样中磷酸盐含量 ${ }^{[4]}$ 。

\subsection{1 实验原理}

酸性介质中, 磷酸根离子和钼酸钠反应, 生成的磷钿杂多酸被氯化亚锡还原, 可得蓝色络合物, 称为磷钼蓝。磷钼蓝的浓度与水中磷酸根含量成正比。在波长 $690 \mathrm{~nm}$ 处以分光光度法测定水样吸光 度, 通过标准曲线即可得出溶液中磷酸根离子的浓度。

\subsection{2 标准曲线的绘制}

移取 $0 、 1.00 、 2.00 、 3.00 、 4.00 、 5.00 \mathrm{~mL}$ 含 $\mathrm{PO}_{4}^{3-} 5.00 \mathrm{mg} \cdot \mathrm{L}^{-1}$ 的磷酸二氢钾标准溶液于 6 个 $25 \mathrm{~mL}$ 比色管中稀释至 $20 \mathrm{~mL}$, 加入 $3.5 \mathrm{~mL}$ 钿酸钠-硫酸溶液, 稀释至刻度。加入 10 滴氯化亚锡甘油溶液, 放置 $15 \mathrm{~min}$ 。将溶液转入 $1 \mathrm{~cm}$ 比色㿼中, 以蒸馏水做参比, 测定并绘制标准曲线。

标准曲线回归方程: $y=0.2807 x-0.0005, R^{2}=0.9996$ 。 $y$ 为吸光度, $x$ 为 $\mathrm{PO}_{4}^{3-}$ 浓度 $\left(\mathrm{mg} \cdot \mathrm{L}^{-1}\right)$ 。

\subsection{3 样品测定}

移取 $10 \mathrm{~mL}$ 过滤后的水样，与绘制标准曲线相同的步骤测定。结果见表 1 。

表 1 水质磷酸盐浓度检测结果

\begin{tabular}{|c|c|c|c|}
\hline 水样号 & 地点与经纬度 & 吸光度 & 磷酸根浓度/( $\left.\mathrm{mg} \cdot \mathrm{L}^{-1}\right)$ \\
\hline \multirow[t]{2}{*}{1} & 重庆千燍门大桥 & 0.009 & 0.09 \\
\hline & $29^{\circ} 33^{\prime} 60 \mathrm{~N}, 106^{\circ} 34^{\prime} 33^{\prime \prime} \mathrm{E}$ & & \\
\hline \multirow[t]{2}{*}{2} & 宜昌夷陵长江大桥 & 0.008 & 0.08 \\
\hline & $30^{\circ} 41^{\prime} 10^{\prime \prime} \mathrm{N}, 111^{\circ} 17^{\prime} 29^{\prime \prime} \mathrm{E}$ & & \\
\hline \multirow[t]{2}{*}{3} & 武汉长江二桥 & 0.016 & 0.15 \\
\hline & $30^{\circ} 28^{\prime} 25^{\prime \prime} \mathrm{N}, 114^{\circ} 25^{\prime} 43^{\prime \prime} \mathrm{E}$ & & \\
\hline \multirow[t]{2}{*}{4} & 上海外滩 & 0.018 & 0.17 \\
\hline & $30^{\circ} 14^{\prime} 19^{\prime \prime} \mathrm{N}, 121^{\circ} 29^{\prime} 10^{\prime \prime} \mathrm{E}$ & & \\
\hline
\end{tabular}

表中数据均为三次测量的平均值 


\section{3 高锰酸盐指数的测定}

高锰酸盐指数是反映水体受有机及无机可氧化物质污染的常用指标，它的大小反映了饮用水、 水源水和地面水受还原性物质污染的程度。 $\mathrm{KMnO}_{4}$ 法分为酸性法和碱性法两种, 氯离子浓度高的水 样常用碱性法。本实验以氧化还原滴定法测定水样的高锰酸盐指数 ${ }^{[5]}$ 。

\subsection{1 实验原理}

水样加入硫酸酸化后, 加入一定量的高锰酸钾标准溶液, 并在沸水浴中加热反应 $30 \mathrm{~min}$ 。剩余 的高锰酸钾加入过量草酸钠溶液还原, 再用高锰酸钾标准溶液回滴过量的草酸钠, 通过计算求出高 锰酸盐指数 $I_{\mathrm{Mn}}$ 。

\subsection{2 实验步骤}

$100.0 \mathrm{~mL}$ 水样依次加入 $5.00 \mathrm{~mL}$ 体积比为 $1: 3$ 的硫酸溶液、 $10.00 \mathrm{~mL} 0.01 \mathrm{~mol} \cdot \mathrm{L}^{-1}$ 高锰酸钾溶 液, 放入沸水浴中加热 $30 \mathrm{~min}$ 。取出, 趁热加入 $10.00 \mathrm{~mL} 0.01000 \mathrm{~mol} \cdot \mathrm{L}^{-1}$ 草酸钠标准溶液, 用高锰 酸钾溶液滴定, 滴定体积 $V_{1}$ 。

取滴定完毕的水样加热至 $70^{\circ} \mathrm{C}$, 准确加入 $10.00 \mathrm{~mL}$ 草酸钠标准溶液, 再用 $0.01 \mathrm{~mol} \cdot \mathrm{L}^{-1}$ 高锰酸 钾溶液滴定至显微红色。记录滴定体积 $V_{2}$ 。

高锰酸盐指数 $\left.I_{\mathrm{Mn}}\left(\mathrm{O}_{2}, \mathrm{mg} \cdot \mathrm{L}^{-1}\right)=\left\{\left(10.00+V_{1}\right) \times 10.00 / V_{2}-10.00\right\} \times c \times 16.0 \times 1000\right\} / 100$ 。 $c$ 为草酸钠 标准溶液的浓度 $\left(\mathrm{mol} \cdot \mathrm{L}^{-1}\right)$ 。

\subsection{3 实验结果}

实验结果如表 2 所示。

表 2 高锰酸盐指数数据

\begin{tabular}{|c|c|c|c|c|}
\hline 水样号 & 地点与经纬度 & $V_{1} / \mathrm{mL}$ & $V_{2} / \mathrm{mL}$ & 高锰酸盐指数 \\
\hline \multirow[t]{2}{*}{1} & 重庆千厮门大桥 & 14.83 & 22.25 & 1.86 \\
\hline & $29^{\circ} 33^{\prime} 60 \mathrm{~N}, 106^{\circ} 34^{\prime} 33^{\prime \prime} \mathrm{E}$ & & & \\
\hline \multirow[t]{2}{*}{2} & 宜昌夷陵长江大桥 & 14.20 & 22.39 & 1.29 \\
\hline & $30^{\circ} 41^{\prime} 10^{\prime \prime} \mathrm{N}, 111^{\circ} 17^{\prime} 29^{\prime \prime} \mathrm{E}$ & & & \\
\hline \multirow[t]{2}{*}{3} & 武汉长江二桥 & 14.76 & 22.68 & 1.47 \\
\hline & $30^{\circ} 28^{\prime} 25^{\prime \prime} \mathrm{N}, 114^{\circ} 25^{\prime} 43^{\prime \prime} \mathrm{E}$ & & & \\
\hline \multirow[t]{2}{*}{4} & 上海外滩 & 16.73 & 22.43 & 3.07 \\
\hline & $30^{\circ} 14^{\prime} 19^{\prime \prime} \mathrm{N}, 121^{\circ} 29^{\prime} 10^{\prime \prime} \mathrm{E}$ & & & \\
\hline
\end{tabular}

表中数据均为三次测量的平均值

\section{3 数据分析与讨论}

\section{1 数据对比分析}

我们将测定数据与地表水环境质量标准 ${ }^{[6]}$ 相对照, 发现 $1 、 2$ 号水样中的磷酸盐含量符合国家二 类地表水环境质量标准, 3、4 号符合三类地表水环境质量标准; 高锰酸盐指数 $1 、 2 、 3$ 号水样都符 合一类标准, 4 号水样符合二类标准。

我们所采集的四个水样, 磷酸盐浓度大小按照城市依次为: 宜昌 $<$ 重庆 $<$ 武汉 $<$ 上海; 高锰酸 盐指数按照城市依次为: 宜昌 $<$ 武汉 $<$ 重庆 $<$ 上海。

\section{2 原因分析}

影响水质的因素主要可以分为自然因素和人为因素。自然因素包括降水量、湿度、温度、植被 分布等; 人为因素包括人口、地区生产总值、地区工业分布等。

4 号水样采自上海外滩, 其高锰酸盐指数和磷酸盐含量在 4 个水样中均为最高。我们认为主要 因素为: 上海市是国际化大都市, 人口众多, 生活污水排放较多, 给水环境特别是流域水质带来很 
大的压力 ${ }^{[7]}$; 同时，上海市地处长江入海口，为下游城市，积累了从上游带来的污染物质。

2 号水样来自宜昌, 3 号水样来自武汉。这两座城市位于长江中上游, 植被覆盖较多。且由于三 峡工程的建设, 宜昌段成为了季节性调节水库, 坝下溶解氧可能出现过饱和现象, 同时三峡建坝后, 枯季供水量增加, 使宜昌段水质得到改善 ${ }^{[8]}$, 武汉也因此受益, 因此2、3 号水样高锰酸盐指数较低。

1 号水样来自重庆, 重庆虽然位于长江上游, 但高锰酸钾盐指数较宜昌和武汉略高。我们分析原 因为: 2011-2018年重庆市流动人口总量呈上升趋势, 流动人口涌入城市, 会产生大量生活垃圾和生 活污水, 给水质带来压力 ${ }^{[9]}$ 。且重庆处于嘉陵江和长江的交汇处, 水流放缓, 来往航运较为繁忙, 可能导致水样水质变差 ${ }^{[10]}$ 。

此外, 我们仅在单一时间点进行了采样, 且受实验条件所限, 仅对水样进行了密封保存的处理, 实验过程中也存在不可避免的测定误差。因此, 我们的实验数据仅可参考, 不能反映水体的整体情 况。

\section{4 社会实践}

2018 年和 2019 年 7 月, 实践队分别进行了两次实践活动。在实践过程中, 除了采集水样、实 验室测定外, 还运行微信公众号、微博, 进行网络调查问卷以及保护水资源实地宣传等实践活动。

\section{1 微信公众号}

团队运行了自己的微信公众号 “绿行之踪” , 出发开始就不断推送消息, 如 “启程第一日” “行 程过半一一我们的第四日” 等。我们通过微信公众号, 不断与大家分享实践过程、困难、经验、教 训与感想，厦门大学社会实践指导中心也对 “绿行之踪”的文章多次转发报道。

\section{2 微博}

社会实践期间，团队通过微博发送每个实践小队的新闻报道。共发送实践新闻 60 余篇，如新浪 微博 “社会实践·我们在路上” 等。“绿行之踪实践队” 相关话题的总浏览量超过 20 万, 被厦门大学 官方微博转发。

每个实践小队通过视频的形式记录取水样的全过程, 同样以微博短视频的形式发送, 相关视频 的播放量突破 4 万。这些视频收获了很多取样地市民的留言, 很多市民对实践队员的做法表示称赞。 团队还积极响应福建省学联号召, 参与大中专学生志愿者 “三下乡” 社会实践活动的宣传报道。

\section{3 实地宣传}

除网络宣传外, 在当地进行防治水污染的实地宣传活动也是我们实践活动的重点。在 2018 和 2019 年的 7 月, 我们携带了队旗、横幅、海报、问卷、纪念品等, 两赴重庆进行了实地宣传活动。

在实践的过程中，队员向市民普及水资源保护小知识, 制作了 300 余个包含 “绿行之踪” 标志 的纪念品, 随机派发给市民, 并且通过宣传、采访等互动方式, 了解市民对于水资源保护的看法和 建议。在活动中, 我们向市民呼吁从自身做起、从身边小事做起、爱护环境保护水资源, 并邀请市 民在相关条幅和海报上签名、合影等。

\section{5 网络问卷调查}

为调查人们对长江流域地表水质污染的了解程度、对长江水污染治理的看法和满意程度, 以及 对于一些水资源保护基本常识的了解程度。“绿行之踪” 实践队发布了水质调查网络问卷, 共回收 问卷 218 份。

\section{1 调查结果统计}

\subsection{1 调查对象基本情况}

调查对象中专业(或职业)与水文或环境有关的人占 $60.09 \%$, 结合图 1 可知, 本次调查问卷主要 反映专业不同的大学生对长江水质现状与保护的认识以及对水资源保护的了解。 

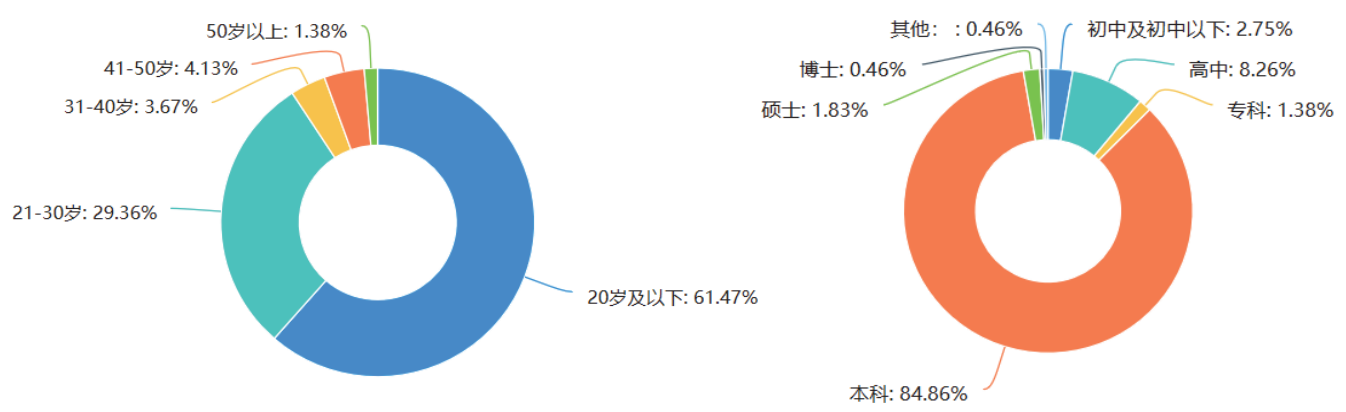

图 1 调查对象的年龄、学历层次分布情况

\subsection{2 调查对象对长江水质现状的认识}

表 3 反映出调查对象对长江水质不了解者居多, 而进一步对了解者调查发现他们信息的来源主 要为新闻报道和网络, 因此, 利用互联网向更多人宣传水质信息和保护水资源是一个很好的方法。

让我们感到不安的是, 选择不了解长江水质的调查对象中, 有 82 人(占比 $55.03 \%$ )的专业与水文、 环境相关。虽然我们数据量有限, 不能全面反映情况, 但是在专业教育方面, 很有必要增强学生对 相关社会实际问题的了解, 做到学以致用。

表 3 调研对象对长江水质信息的了解情况

\begin{tabular}{ccc}
\hline 是否了解长江水质信息 & 专业与水文、环境有关 & 专业与水文、环境无关 \\
\hline 了解 69 人 & 49 人 & 20 人 \\
不了解 149 人 & 82 人 & 67 人 \\
\hline
\end{tabular}

表 4 反映了调查对象对长江水质的满意程度，评分集中区间是 41-60 分，平均值为 55.97 分, 说明参与调查人群对长江水质的满意程度介于一般到满意之间。由于样本中部分调研对象对长江水 质不甚了解，他们主要依据自己的印象评分，因此此项评分只能作为参考。

表 4 调研对象对长江流域水质的评分情况

\begin{tabular}{cccccc}
\hline 评分区间 & $0-20$ & $21-40$ & $41-60$ & $61-80$ & $81-100$ \\
\hline 人数 & 10 & 28 & 93 & 69 & 18 \\
\hline
\end{tabular}

另外, 进一步的调研反映, 不少调查对象认为长江流域现在面临着生物多样性减少、水质污染、 湖泊面积缩小、泄洪能力差、水土流失等问题。因为经济的快速发展对水资源的保护带来压力, 并 且水资源的开发利用会引发新的生态环境问题, 而长江流域面积大、河流长度长也为治理水质情况 增加了难度。

\subsection{3 调查对象的水资源保护意识}

表 5 是对调查对象水资源保护意识的调查, 令我们感到欣慰的是, 绝大多数调查对象具有保护 水资源的意识, 并且在调查中表示会落实到生活小事中, 如不向河流中扔垃圾、倒污水, 不在河边 洗衣服等。但若是面对他人污染水质, 则有 $27.52 \%$ 的调查对象认为自己不会主动劝说、阻止。相较 于去劝说、阻止他人污染水质的行为，调查对象更愿意自己做一些力所能及的保护水资源的小事。

对于保护水资源, 有调研对象认为, 普通人只能尽微薄之力, 特别是工业污染等环境问题, 需 要政府政策方针的支持才能真正落到实处; 大部分调研对象认为了解政府对污染的整治方案以及个 人保护水资源的方法很有必要。因此, 我们不仅要宣传保护水资源的重要性, 更要普及相关政策法 规和具体措施的实施。 
表 5 调研对象保护水资源的意识

\begin{tabular}{ccc}
\hline 是否具有保护水资源的意识 & 专业与水文、环境有关 & 专业与水文、环境无关 \\
\hline 具有 208 人 & 125 人 & 83 人 \\
不具有 10 人 & 6 人 & 4 人 \\
\hline
\end{tabular}

\section{6 感想与收获}

\section{1 巩固与提升了基础知识}

这次实验是我们在查阅国标、文献资料等基础上自主完成的。我们把在无机和分析化所学的书 本知识运用到实践中, 巩固了基础知识; 同时在查阅文献的过程中, 学到了新的知识、提高了认知 水平。

\section{2 培养了自身能力}

水样的测定并不是像我们一开始想象的那样顺利, 遇到了不少现象异常等意外情况, 如由于 $\mathrm{SnCl}_{2}$ 被氧化而导致标准溶液不显色等。每当遇到问题, 我们都积极思考、分析原因, 进而解决问题。 这锻炼了我们自主思考和灵活应变能力, 提升了我们的实验水平, 培养了我们的动手能力和实践能 力。同时, 我们还掌握了运行公众号, 以及制作视频、答辩、撰写项目书、设计问卷题目等技能, 综合能力得到了提升。

\section{3 磨砥了意志品质}

实践活动在夏天进行, 重庆、武汉等城市都十分炎热, 且取水过程遇到了不少困难。比如, 在 第一次取水时, 由于长绳缠绕打结未取到水, 浪费了许多时间; 也遇到取水器漏水, 临时买桶取水 等预先想不到的问题。在实践中, 我们想方设法、克服困难, 完成了任务。实践经历是对我们意志 力的一次磨练, 培养了我们吃苦耐劳的精神。

\section{4 增强了社会责任感}

调查等实践活动让我们对于长江水质有了更为深刻的了解, 认识到保护水资源的重要性。我们 深感, 保护水质要从点滴做起、从自己身边做起。社会主义生态文明建设是社会主义现代化建设的 重要内容，需要个人、企业、政府合力营造良好的生态环境。

这次社会实践活动, 促进了我们对社会的了解, 增加了我们对祖国山河的热爱, 实现了书本知 识和社会实际的更好结合。同时, 帮助我们树立了正确的世界观、人生观和价值观, 增强了我们的 社会责任感。

致谢：本水样测试实验在厦门大学化学国家级实验教学示范中心完成, 特此表示感谢!

\section{参 考 文 献}

[1] 蒋溢真. 数码世界, 2019, No. 1, 43 .

[2]２018 年中国水资源公报. [2019-11-30]. http://www.mwr.gov.cn/sj/tjgb/szygb/201907/t20190712_1349118.html.

[3] 林君铿, 涂文子, 梁永津, 赵彦龙. 理化检验(化学分册), 2014, 50 (1), 130.

[4] 循环水中磷酸根的测定一磷钿蓝比色法. [2020-04-12]. https://wenku.baidu.com/view/5c9765f965ce050877321339.html.

[5] 国家技术监督局. 水质 高锰酸盐指数的测定. GB/T 11892-1989. 1990-07-01.

[6] 国家环境保护总局, 国家质量监督检验检疫总局. 地表水环境质量标准. GB 3838-2002. 2002-06-01.

[7] 谭凌智, 蒋静. 人民长江, 2012, 43 (12), 50.

［8］何国瑜. 海洋湖沼通报, 1990, No. 1, 11 .

[9] 陈知丹. 现代商业, 2020, No. 2, 83.

[10] 张丽, 胡天鹏. 湖北理工学院学报, 2019, 35 (4), 18. 